Илья Утехин, Анна Алтухова, Анна Клепикова

\title{
ИНТЕЛЛЕКТУАЛЬНАЯ ИНВАЛИДНОСТЬ И РАССКАЗЫ ИЗ ЖИЗНИ: НАБЛЮДЕНИЯ НАД УСТНЫМИ НАРРАТИВАМИ
}

Устные повествования о жизненном опыте молодых людей с «легкой степенью умственной отсталости» и опытом проживания в коррекционных учреждениях закрытого типа собраны в ходе полуструктурированных интервью и в разговорах в рамках полевого исследования, проведенного в небольшом российском городе. Все рассказчики в тот момент участвовали в проекте сопровождаемого проживания, организованного НКО, позволившей участникам покинуть специализированные учреждения. Из-за отсутствия или неадекватности школьного образования большинство информантов близки к функциональной неграмотности. Один из примеров рассказа, проанализированный в статье, принадлежит категории страшных историй из жизни в семье или в учреждении. Рассказчики редко оказываются в ситуации, когда им надо представлять себя перед кем-то извне знакомого круга подопечных проекта и социальных работников, и их рассказы так или иначе уже циркулировали в этом «своем» кругу. Рассмотрены дискурсивные особенности нарративов, представляющих собой часть диалогового взаимодействия. Для этих рассказчиков главным способом рассказывания оказывается театрализованное разыгрывание истории с переводом ее в диалог героев, который цитируется в виде прямой речи. Выявленные особенности отличают устные повествования, не испытавшие на себе воздействия письменной культуры и школьного «развития речи». При рассмотрении

Илья Владимирович Утехин- к.ист.н., доцент, факультет антропологии, Европейский университет в Санкт-Петербурге, Россия. Электронная почта: ilia@eu.spb.ru

Анна Николаевна Алтухова- магистр антропологии, научный сотрудник, Институт междисциплинарных медицинских исследований, Европейский университет в СанктПетербурге, Россия. Электронная почта: aaltukhova@eu.spb.ru

Анна Александровна Клепикова-к.социол.н., доцент, факультет антропологии, Европейский университет в Санкт-Петербурге, Россия. Электронная почта: aklepikova@eu.spb.ru 
рамочных выражений и дискурсных маркеров в рассказах обнаружено, что некоторые типы выражений, обычно передающие отношение рассказчика и демонстрирующие его рефлексию, отсутствуют в рассматриваемом материале. Повествования демонстрируют тяготение рассказчиков к использованию сочинительных связей (вместо подчинительных, выражающих причинные отношения). К сожалению, изложенные в статье наблюдения являются результатом пилотного исследования и не могут претендовать на то, чтобы быть характеристиками рассказывания историй людьми с умственными особенностями, поскольку в ходе данного исследовательского проекта не предполагалось проводить сравнение с аналогичными рассказами других людей с сопоставимым опытом социализации в специализированных учреждениях.

Ключевые слова: дискурс, устный нарратив, рассказывание историй, интеллектуальная инвалидность

DOI: 10.17323/727-0634-2021-19-4-619-634

Исходной точкой статьи было любопытство авторов по отношению к форме рассказывания историй из своей жизни, которую мы встретили в группе наших информантов- молодых людей с диагнозом «легкая умственная отсталость». Все они - выпускники коррекционного детского дома-интерната и около десяти лет участвуют в проекте сопровождаемого проживания. Все наши информанты и в ситуации обычного разговора, и в неструктурированном интервью рассказывали истории. В случае интервью эти истории спровоцированы интересом исследователей к биографии информантов, в спонтанной беседе повествовательные фрагменты всплывали как они к месту всплывают обычно в разговоре. Несмотря на то, что речь информантов очевидно выглядела более «бедной», менее «грамотной» и более насыщенной диалектизмами, чем, например, речь социальных работников и педагогов, информанты демонстрировали, что рассказывание случаев и историй из жизни- органическая часть их разговорных навыков, не требующая каких-то особенных усилий. Однако чувствовалось что-то общее и непривычное в том, как информанты строят рассказы. И прежде чем пытаться объяснить эти особенности, мы решили их сформулировать, чему, собственно, и посвящена эта статья.

\section{Сироты с диагнозом «умственная отсталость» в проекте сопровождаемого проживания}

Советская система государственной заботы о сиротах с интеллектуальной инвалидностью состояла из учреждений двух типов: коррекционных школ-интернатов (VII и VIII вида- для детей с задержкой психического развития и умственной отсталостью соответственно) и детских домовинтернатов, куда попадали «необучаемые» дети- такие, которые были 
признаны неспособными к получению даже урезанного образования в виде программы первых трех начальных классов (то есть к освоению программы школы VIII вида). После распада СССР она почти без изменений продолжала функционировать еще почти два десятилетия; единственное, что поменялось существенно-это категории детей, туда попадавших (Stepanova 2014: 38-40). Многие учреждения приобрели статус сиротских, наполнившись огромным количеством детей, чьи родители пили или не заботились о них должным образом (Rockhill 2010; Schmidt 2009).

Дети из неблагополучных, часто многодетных семей нередко попадали сразу в коррекционные, а не в общеобразовательные школы (Hunt 1998). Как показывают материалы полевой работы, большинство учеников таких интернатов могли рассчитывать в дальнейшем на поступление в ПТУ на ограниченное число специальностей и на вполне «обычную» взрослую жизнь после окончания училища. Но многие воспитанники и училищ, и коррекционных школ на том или ином этапе все равно оказывались во взрослых психоневрологических интернатах (ПНИ). Другая часть учеников коррекционных школ отсеивалась и попадала в детские домаинтернаты, где никакого образования не было. Причиной попадания в детский дом-интернат в 1990-х и начале 2000-х гг. могло быть «плохое поведение» ребенка (Stepanova 2014; Rockhill 2010). Для этих детей никакого иного варианта взрослой жизни, кроме как пребывания в ПНИ, не предполагалось. После совершеннолетия их могли забрать к себе родственники, но это не распространенная практика.

Альтернативу такому сценарию для крайне ограниченного числа детей предлагали благотворительные фонды. Тот, что попал в фокус нашего внимания, разрабатывал две стратегии помощи: устройство детей в приемные семьи (зачастую в семьи местных фермеров или бывших работников самого детского дома-интерната-ДДИ) и открытие квартир сопровождаемого проживания, куда бывшие воспитанники ДДИ могли переехать после совершеннолетия и «учиться жить самостоятельно». Помимо чисто бытовых навыков (приготовление еды, уборка, оплата счетов), сотрудники благотворительной организации старались дать своим подопечным и другие: поскольку многие попали в ДДИ еще в начальной школе, они не умели ни читать, ни считать, ни писать.

Нашими информантами стали участники проекта сопровождаемого проживания, созданного НКО «Первоцвет» в одном из аграрных регионов центральной России, которая на момент исследования (2018-2019) предоставляла жилье и круглосуточно сопровождала тринадцать человек, а также курировала более двадцати человек, которые «выпустились» из квартир сопровождаемого проживания и, благодаря содействию НКО, получили собственные квартиры по программе социального жилья от государства. Нашими информантами стали двадцать восемь человек, но героиней этой статьи будет Надя (25 лет). Она живет в маленьком городе 
Рухов, в собственной квартире, которую предоставило государство, но с поддержкой НКО. В свое время она успешно доказала педагогам НКО, что может жить без постоянного сопровождения. Для них это означает уверенность в безопасности подопечных.

Интервью с бывшими подопечным коррекционного детского дома посвящены их биографиям- мы просили рассказать нам все, что они помнят о своей жизни: о времени, проведенном в семье и в учреждениях, о том, как им удалось оттуда выйти и как они живут сейчас. Мы поговорили с информантами более одного раза, наблюдая за тем, как менялись их рассказы о себе. Вопрос о том, как в целом устроен биографический нарратив человека, который провел большую часть жизни в детском доме и не умел или не умеет до сих пор читать и писать, заслуживает отдельного обсуждения. Заметим, что в первые наши встречи информанты пытались произвести впечатление на нас и прибегали к одному и тому же средству: они рассказывали о своей жизни в жанре «ужасных историй», наполненных многочисленными подробностями, которые должны были тронуть, удивить слушателя, заставить его сопереживать, но в дальнейшем общении акценты сместились на разговоры о более простых и повседневных вещах.

Часть рассказов собраны в жанре «интервью», другие приближены к неформальной беседе (вечером на кухне, за совместным обедом, во время прогулок), хотя наш статус как интервьюеров все равно имел значение и в этих моментах. За все время полевой работы (несколько выездов в поле с января 2018 по октябрь 2019 гг.) собрано тридцать восемь интервью с 28 подопечными НКО длительностью от сорока минут до трех часов. В обсуждении Надиного интервью мы также расскажем об интервью с Алексеем. Обе эти истории относятся к текстам, собранным в жанре интервью, и к первому этапу сбора материала. И Надя, и Алексей в обоих случаях понимали, что происходит запись разговора и что это «настоящее интервью». Многие наши информанты не раз беседовали в таком формате с журналистами и документалистами, поэтому этот жанр им знаком.

\section{Устный нарратив и атипичные популяции}

Рассказывание историй как жанр устной речи и как часть разговорного взаимодействия становилось предметом внимания социолингвистов начиная с 1960-х гг., когда появилась знаменитая работа Уильяма Лабова и Джошуа Валецки (Labov, Walezky 1967) с анализом рассказов из жизни, собранных у людей с низким уровнем образования. Три десятилетия спустя Эмануил Щеглов указал на то, что авторы этого классического текста использовали термин «устная версия рассказа о собственном опыте», чтобы подчеркнуть разницу между устной и письменной речью, но тот факт, что рассказы были собраны в ходе социолингвистического интервью, не был важен для них (Schegloff 1997). Между тем восходящая к Харви 
Саксу линия интеракционной микросоциолингвистики обращается к тому, как то или иное действие в разговоре встраивается в социальное взаимодействие. Эта перспектива рассмотрения исходит из представлений, согласно которым, когда люди что-то рассказывают по большей части они не делают это просто так, а что-то совершают посредством своего рассказа - хвастаются, жалуются, поддразнивают, объясняются или оправдываются, сообщают информацию, отвечают на вопросы или реагируют на другие, ранее рассказанные истории. Так, история, оказавшись в определенном месте разговора, должна своим появлением давать участникам разговора ответ на вопрос «почему это здесь?» (там же). Это означает, что рассказывание истории не просто ориентировано на аудиторию, а предполагает совместную работу участников разговора. Соответственно, исследователю нужно показать эту работу- например, как история вводится в разговор и зацепляется за текущий контекст: на что ориентируются участники, распознавая высказывание как историю, ведь они должны были понять, что собеседник собирается развернуть нарративное высказывание, чтобы предпринять на время рассказывания специфическую модификацию механизма смены говорящего (turn) - так, чтобы у рассказчика была трибуна, которая ему передается как некоторый кредит доверия (Sacks 1974; Jefferson 1978; Mandelbaum 2013:493). В рамках этой статьи, однако, анализ будет сосредоточен скорее не на конверсационной механике, а на тематическом и структурном анализе повествований.

Как указывал Ирвин Гофман (Goffman 1974: 504-505), нарративный ответ в разговоре это не просто сообщение о событии, это проигрывание собственного опыта в определенной перспективе, одной из множества возможных, в такой, которая позволяет слушателям встать на место участника события - с разной степенью драматизации. Зачастую это изображение в настоящем времени, где говорящий и герой повествования- одно лицо. В ходе взаимодействия участники периодически меняют характер своей включенности (footing, в терминологии Гофмана), например, когда мы переключаемся от говорения от себя к пересказу или цитированию слов другого, в том числе, если этот другой- наше собственное воплощение в ситуации, о которой мы рассказываем (Goffman 1981: 151). Это значит, что разные употребления личного местоимения «я» оказываются благодатным материалом для анализа: тот «я», который имеется в виду, может быть отнесен во времени от момента разговора. Кроме того, в разговоре переключаются фреймы, которые могут либо вводиться специальными словами и выражениями, дискурсными маркерами, а могут не быть внешне выражены словесно (к смене фрейма могут отсылать изменение громкости, скорости, высоты и тона голоса, просодическое выделение). Внимание к фреймовым переходам и их проявлениям закономерно в свете интереса Гофмана (и конверсационного анализа) к интерактивному аспекту разговора. Между тем наш интерес к явлениям из области фреймирования и характера включенности 
говорящего связан с тем, что они позволяют увидеть ходы в разговоре как действия, связанные с конструированием себя в разговоре- это работа по разыгрыванию своей идентичности в нарративе (Ribeiro 2006: 50).

Поскольку некоторые особенности рассказывания историй у информантов могут быть связаны с тем, что они не получили начального образования и плохо владеют грамотой, мы имеем в виду результаты экспериментального исследования нарративной компетенции «функционально неграмотных» взрослых, не справившихся с освоением школьной программы (Eme et al. 2010). В сравнении с рассказами по картинкам грамотных взрослых, рассказы неграмотных оказались короче и характеризовались меньшей вариативностью синтаксических конструкций, не всегда прозрачными и менее разнообразными, чем у грамотных, средствами анафоры, в целом менее явной связностью-что отчасти объясняется непроговариванием причинных связей и информации о целях и интенциях персонажей; грамотные рассказчики значительно чаще прибегают к описанию психологических состояний. Эти наблюдения существенны для нас даже притом, что в нашем материале речь идет не о рассказывании по картинкам в рамках эксперимента, а о другом жанре.

В нашем подходе к нарративам, полученным от людей с когнитивными отличиями, мы принимаем во внимание методы и результаты ряда работ, посвященных исследованиям рассказов представителей атипичных популяций, так или иначе сходных с нашими информантами. Американский антрополог Майкл Ангрозино одним из первых предложил работать с текстами, полученными в результате диалога исследователя и человека с интеллектуальной инвалидностью (Angrosino 1997). Он указал, казалось бы, на очевидную вещь, что его собеседники, имевшие опыт институциализации и интеллектуальные отличия, стремились в беседе с антропологом к тому, чтобы создать удовлетворяющий их образ самих себя. Но поскольку многие из них не имели навыка рассказывать длинные истории, нарратив о себе становился продуктом совместного труда исследователя и информанта. В более ранней статье, анализируя все те же тексты, Ангрозино заметил, что его собеседники нередко создавали нарративы, похожие на поток: информанты, цепляясь за отдельные слова или выражения, перетекали из одного сюжета в другой, не заканчивая их. Но при этом если структурно эти тексты представляли собой хаос, общетематически они были выдержаны в одном ключе- презентации себя другому. Ангрозино охарактеризовал эти нарративы как роetic narratives (Angrosino 1992: 181).

Со схожим материалом работала американский антрополог Анна Лоувел: она собирала биографические нарративы среди бездомных с психиатрическими диагнозами (Lovell 1997). Как и информанты Ангрозино, бездомные, с которыми говорила Лоувел, хотели бы в рассказе о себе создать такой образ, который бы противостоял распространенному представлению о них как о маргиналах. Как и рассказы собеседников Ангрозино, истории инфор- 
мантов Лоувелл не похожи на обычные нарративы: их интерпретация требовала длительного и внимательного знакомства с этими людьми для того, чтобы расшифровать то, что они сообщали о себе, как правило, в коротких и запутанных в восприятии «внешнего» слушателя высказываниях.

\section{Устные рассказы о случаях из жизни: заметки к анализу}

Поскольку за плечами у рассказчиков с формально диагностированной задержкой интеллектуального развития, действительно трудные жизненные ситуации, в их распоряжении оказывается биографический материал, из которого они могут подбирать эпизоды, чтобы сформировать уместную по обстоятельствам самопрезентацию. Рассмотрим это на примере рассказа Нади. Интервью она давала вместе со своим молодым человеком Гришей (тоже подопечным НКО) у себя дома. В те моменты, когда говорила Надя, Гриша молчал. В транскрипции этот преимущественно монологический фрагмент разговора разбит на единицы, образующие просодическую целостность.

Действующие лица- участники событий: Надя; Даня, брат Нади; Оксана, сестра Нади; Петр, отец Нади; Гена, брат отца Нади; Светлана, мать Нади; Неля, сестра отца Нади; Валентина, психолог благотворительной организации.

H: $\quad$ Хорошо, что мы друг друга нашли, и вот Даня мне звонил, я тут плакала, и он плакал. И он говорит: Надя, я так хочу тебя, говорит, увидеть, приехать. Я говорю: ну когда-нибудь встретимся с тобой. Вот. Встретимся, я говорю: ой, если мы встретимся, я говорю, < там расплачусь/yль$б а я с ь>$ >. И он тоже говорит: ну я тоже. И он всегда, когда мне звонит, он всегда плачет. Я говорю: Даня, не плачь, а то я буду тоже плакать. *И вот мы друг друга нашли и общаемся с ним*. И по интернету, и по телефону, и тогда, когда в Питер позвонила ему, он мне < сразу с телефона все деньги ушли/улыбаясь > вот. Вот так мы и общаемся. Ну я с тетей щас общаюсь и с Данечкой общаюсь.

Инт: А с сестрой?

H: А вот с сестрой, сестра... Сестру мою... У меня сестра была, сестра родная Оксана была, ${ }^{*}$ ну ее убили.* Вот, сестру. Она, короче, () ну, короче, () она у нее муж был, но она была гулящая. Со всеми, со всеми, с этими там дальнобойщиками, с цыганями, ну и она, короче, что-то пообещала и не выполнила, с автобуса выходит, и ее, короче, убили. Потом мне () в приюте звонят, говорят: Надь, твою *сестру убили*, я сильно плакала.

И вот тоже у сестры не была на похоронах [потому что была в интернате] Я только была на похоронах, когда дома у папы, когда папа умер, 
я была у папы, у папы- тьфу, тьфу, тьфу- вот так пальцы были отмерзнуты, вот, он лежал в больнице, у него отмерзнут пальцы были. Лежал в больнице, и потом эта () аргена пошла по ноге, по ногам, и он, короче, умер в больнице.

И мне сказали, что папа умер, и мы, короче, возили, забирали его с морга, потом батю забирали с морга, он у нас дома ночью стоял, я сильно плакала по папы. Потом его отпевали, я стояла, и потом мы все потом его хоронили.

И вот у меня и дед [дядя], вот папин брат, папин брат, он к нам прибежал, еще папа жив был, и говорит: Ген, говорит, что ты такой, голит, грустный? А мы это, папа увидел, что у него в виске, ну, кровь идет! Папа говорит: а что у тебя в виске кровь? Он говорит: это ему нож... он говорит это мне ножиком заехали. И он прямо у нас дома у папы на глазах и умер! Папа в слезы, я говорю: пап, чего ты плачешь? Он говорит: у меня брат умер, грит, надо хоронить, грит! Я говорю: ой, пап, я грю, я тебя поддерживаю.

А когда вот папа умер, и папина тетя, ну сестра [Неля], говорит: вот, говорит, Ольгу мы похоронили, сестру мою, и грит, ты почему, грит, на гроб не дал деньги? Она [Неля] говорит, тетя говорит: ты когда умрешь, также и мы тебя, говорит, как собаку грит похороним! Тоже, говорит, деньги не дам на гроб! Говорит: ты зараза, ты такая, сест... дочка, грит, умерла, а ты тут пьешь! Ее надо хоронить, а ты, грит, тут бухаешь. А он говорит... а та... тетя говорит: а ты, Свет, что? А она [мать Нади] пьяная, рот не открывается: а что? [изображает], такая. Я, ну тетя говорит: Оксана умерла, ее надо хоронить, говорит, надо деньги на похороны. А она говорит: а мы ее хоронить не будем! говорит, хорони сама, говорит. Тетя говорит: хорошо, говорит, вы еще, говорит, обратитесь ко мне, ну а ты, говорит, Петь, когда умрешь, говорит, я тоже, говорит, не буду хоронить. *Она его напугала*, говорит: я тебя, говорит, в яме закопаю [смеется], когда ты умрешь. А потом, а потом тетя его напугала, а когда он уже умер, тетя говорит: я же его напугала, грит, а так я же его, правда, говорит, похороню. Это. И вот когда он умер, и вот я ездила к тете, на Троицу мы ездили, я ездила, я была на Троице, и мы ходили на, это, на кладбище. Я к папе ходила, к бабушке ходила, бабушка тоже умерла. Потом к сестры ходила, так *сильно-сильно плакала*. Вот. Короче, я очень много, много-много-много-много в своей жизни плохое пережила, вот.

И вот тетя, тетя всегда Валентине [психологу] говорит: пожалуйста, говорит, берегите Надю, грит, она очень так плохо пережила, говорит, она, говорит, это.. мама ее била, папа ее бил, говорит, никто, говорит, не любил, говорит, кроме меня, но вот берегите ее, грит. Она очень-оченьочень много пережила. А Валентина говорит: да, мы верим. Да, говорит, говорит, мы верим. И вот когда она Валентине это все рассказала, Валентина была просто... в ударе. После тетиных слов. Она говорит: ужас. 
() Она говорит: вот, Надя, говорит, сколько ты, говорит, пережила. Я говорю да. Вот. И она, она, тетя говорит: и похороны она пережила, и вот эту пьянку, говорит, все пережила, молодец, говорит. И вот, и тетя мне всегда говорит: Надь, не будь такой, как Оксана, не будь. Не будь, говорит. Вот полюбишь одного пацана, вот и люби, говорит, одного мальчишку, а не будь, говорит [смеется], как Оксана, грит. Совсем своих родных не бери в пример, как они, говорит, с тобой. И даже семья, грит, твоя, говорит, когда семья твоя будет, так, говорит, не делай, говорит, ребенка не бросай, говорит. Не пей, говорит, не кури, говорит. Совсем, говорит. Вот. (1.0) *Вот так.*

Эта цепочка историй про смерти и похороны родственников- сестра, отец, дядя- на фоне пьянства, насилия, пренебрежения родительскими обязанностями, которую выстраивает Надя, встроена в разговор о семейных связях. Вообще, тот факт, что у выходцев из интерната есть родственники, хотя бы где-то далеко, представляет собой для них важный компонент идентичности и своеобразный социальный капитал, даже если связи эти не предполагают регулярного общения и близких отношений. Итогом Надиного повествования оказывается длинный пассаж о том, сколько Надя пережила и какой моральный урок преподносит Наде положительный герой ее истории, ее тетя, о важности верности своей семье (созданной с сидящим рядом «пацаном», а не родной семье) и здорового образа жизни. Цельные высказывания, которыми Надя объясняет свою жизнь, скорее всего, заимствованы от педагогов. Фигура психолога Валентины привлекается в качестве «авторитетного свидетеля», который призван подтвердить и усилить впечатление, производимое рассказом на слушателя.

На том этапе работы с информантами, когда были записаны рассказы, исследователь воспринимался ими как представитель внешнего мира-как воспринимался бы, например, журналист. Соответственно, самопрезентация перед таким собеседником предполагала выстраивание такого образа себя, который демонстрирует одновременно и экстремальную тяжесть перенесенных в детстве испытаний (как в семье, так и в интернатской системе), и свою успешную адаптацию к внешнему миру, освоение ценностных ориентиров «нормальной» жизни. Надя-молодец, она «все пережила», всё это осталось в прошлом, при этом она твердо знает, как не надо себя вести.

Рассказывая о пережитых событиях, Надя повторяет одну и ту же деталь (как она плакала), которая оказывается и итогом каждого из эпизодов (разговор с братом, гибель сестры, смерть отца, поход на кладбище), и одним из способов связать эпизоды воедино: все они о тяжести пережитого. Плачет не только Надя, плачет и ее отец, когда умирает его брат. В момент рассказа Надя явно волнуется: в транскрипции было бы затруднительно показать ее дыхание, но и в записи слышно, что ей как будто не хватает воздуха. Однако она переживает не те эмоции, о которых она упоминает, 
а смотрит на персонажей этого рассказа, наверняка неоднократно уже представленного в похожей форме разным слушателям, отстраненно, подобно тому как если бы она рассказывала страшную фольклорную историю, без всякой связи с реальностью. Надя в нескольких местах смеется, этот смех не выражает радостных чувств, но работает в разговоре как интеракционный показатель, маркируя те моменты, где могла бы быть сильная эмоциональная реакция; она ожидается от слушателя.

Последовательность рассказывания эпизодов (и внутри эпизодов- последовательность презентации деталей) не отражает реальной хронологии, но для рассказчика хронологическая связность не важна, не она организует эпизоды в целостное повествование. Надя местами не вполне справляется с формальными средствами организации текста: например, эпизод вводится словами «А когда вот папа умер», а дальше идет изложение диалога тетки с отцом (то есть понимать это вводное выражение следовало бы скорее как «а что касается папиной смерти»). Эпизоды практически не содержат описаний обстоятельств, ситуаций и персонажей. При этом эпизод со смертью Гены передается так, как если бы Надя была его свидетелем, а слова «я тебя поддерживаю» исходят от сознательного человека. В реальности ей было в тот момент не больше семи лет, и она находилась в интернате, то есть история известна ей со слов родственников.

Элементы рассказа-«страшилки», призванного воздействовать на слушателя в том числе и нагнетанием повторяющихся ужасов, вставлены в рамочную конструкцию, привязывающую рассказ к актуальной ситуации, к ответу на вопрос кто такая Надя сегодня. В обрамлении последовательности эпизодов присутствуют авторитетные фигуры- тетка Нади и психолог благотворительной организации, словами которых и выражается общий смысл рассказа. Отметим, что и в этом примере передача прямой речи персонажей образует значительную часть собственно рассказа о событиях. Нельзя не заметить, что во всех этих эпизодах Надя только переживает события, она оказывается жертвой обстоятельств и не совершает каких-либо самостоятельных поступков, ее судьба целиком определяется обстоятельствами и поступками других людей, а у самой Нади почти отсутствует агентность. Это не значит, что Надя в принципе последовательно придерживается такой стратегии саморепрезентации, потому что в других рассказах, не следующих жанровым принципам «страшилки», она демонстрирует свою самостоятельность.

\section{Обсуждение}

Наша рассказчица, как и другие участники нашего исследования, изображает действие через речь героев повествования, которая практически не бывает оформлена как косвенная речь, а вводится как цитата либо рамочной конструкцией «я говорю/он говорит» и интонацией, причем эта 
конструкция тяготеет к статусу дискурсного маркера. Также в этой функции выступают дискурсные маркеры «говорю/говорит» в разных вариантах. Дебра Шифрин в качестве операционального определения предлагает рассматривать дискурсные маркеры как секвенционально зависимые элементы, заключающие единицы разговора в скобки (Schiffirin 1987:31-32); эти границы могут относиться к разным уровням организации разговора.

При этом фреймирующая функция дискурсных маркеров может относиться к речи рассказчика на разных уровнях. Например, маркер «вот» может выступать здесь в разных функциях, относящихся к разным ролям говорящего: в нашем примере «вот» выражают границы повествовательных сегментов и отмечать потенциальные точки перехода очереди говорящего (Я1, говорящий как участник разговора), другие «вот» организуют развитие рассказа - вводят новую тему внутри рассказа (аналогичны начальному союзу «и») и относятся к роли говорящего как автора рассказа (Я2); есть и такие «вот», которые расположены в цитируемой речи персонажа. Можно было бы сказать, что эти «вот»- омонимы, но их сочетание в рассказе, их повторение придает ему дополнительную связность. В целом дискурсные маркеры указывают на связь высказывания с уже сказанным, с тем, что будет сказано, с позицией рассказчика и апеллируют к вниманию адресата. При этом некоторые типы фреймирующих показателей, связанных с выражением позиции говорящего (например, «по правде говоря», «к сожалению», «тем более», «в конце концов» и т.п.) в рассказах не встречаются. Можно было бы указать на тот факт, что все они стилистически чужды речи наших информантов, как оказываются невостребованными и соответствующие значения. Соположение, сочинительные связи и дискурсные маркеры оказываются на месте тех связующих элементов рассказа, где в условной «грамотной речи» оказались бы подчинительные связи, выражающие такие отношения как причинность.

Рассказ, адресованный слушателю, может в разной степени учитывать перспективу слушателя. Учет позиции получателя и соответствующая ориентация высказывания (recipient design) является одним из фундаментальных принципов разговорного взаимодействия (Levinson 2006), причем выбор среди возможных обозначений людей и предметов- прототипический пример учета представлений собеседника (cp. Sacks 1992: 148-149). В наших примерах систематически встречаются реплики, содержание которых могло бы вызвать вопросы непосвященного слушателя, а исследователь не относился к числу посвященных в подробности жизни рассказчика. При этом собственно рассказ не сопровождается пояснениями и комментариями, ориентированными на такого слушателя.

Столкнувшись с тем, что такие рассказы, как Надин, практически не включают адресованных слушателю ретроспективных комментариев и оценок собственных действий и мыслей, мы обратились к другим имеющимся в записях диалогам и поискали нарративные ответы на вопросы 
в интервью, а также такие упоминания о собственном прошлом, которые не носят характера сколько-нибудь развернутого повествования и не оформлены как рассказываемая история, а появляются как ответ на вопрос. Оказалось, что у того, кто успешно закончил коррекционную школу и свободно читает, в диалоге присутствуют многие из тех компонентов рассказывания, которые не встречались в историях-«страшилках», такие как метакоммуникативные высказывания и отсылки к своим мыслям в разных временных планах. В примере ниже они подчеркнуты в рассказе Алексея, полученного в формате интервью у него дома:

Инт: Слушай, а ты вот с отцом Сергием поддерживаешь отношения?

A: Нy, не скажу, что прямо плотно, но, бывает, встречаемся, здороваемся, общаемся. Вот. Летом я к нему в гости приезжал, наверное, раза два. Мы редко видимся с ним. Поначалу, я как бы помню, что его оскорблял, я, я очень долго не мог извиниться перед ним, ну, просто страшно, а вдруг человек не захочет разговаривать, да, что, собственно говоря, первый раз и было. Я позвонил, у меня голос трясется, ну, просто страх было не осилить. Потом думаю, когда уже сюда приехал, отчислился, сколько про себя думал: а сколько можно бегать от того, что все равно как бы... от, простите, обзывая, оскорбляя кого-то, человек думает, что а дорожка больше не сведет, не сведет, не судьба больше сойтись. Я был того же мнения поначалу, но организация Первоцвет, ну, вытянула. Стукнула мысля такая в голову: а сколько можно бегать-то? Давай-ка ты уже, иди, извинись. Я понимаю, по телефону легко, ты не видишь этого человека, ты не видишь его ощущений, что он чувствует. Ты не видишь его лицая привык, собственно говоря, все вживую высказывать, также и за общение за живое. Я позвонил ему: ну опять же, здравствуйте, отец Сергий, это мне дал Дима номер. Вот. Я извинялся. Он меня в гости пригласил, мы, в общем, поговорили, так, на дружеской ноте, нормально все так стало. Я ему, я, конечно же, раскаялся, что я согласен, что с моей стороны это было неправильно. Ну, в общем, не скажу, что там каждый день, каждые выходные к нему езжу, нет. Но дружим.

Такой стиль рассказывания отличается от истории, представленной выше, в целом ряде отношений, в том числе тем, что здесь зацепление за текущий контекст разговора распределено в самом рассказе, а не только локализовано в рамочной конструкции начала и конца реплики, и тем, что перформанс цитирования прямой речи персонажей не является главным способом организации повествования. В результате проявления субъективной позиции оказываются богаче и разнообразнее, включая выражения металингвистического характера («не скажу, что ..., но ...»).

В отличие от большинства наших информантов, Алексей свободно умеет писать, читать и считать. «Легкая степень умственной отсталости» у него 
и у других информантов нередко диагностировалась на основании скорее бюрократических причин, при том, что поведенческие особенности и общий уровень развития могли быть результатом педагогической запущенности и социализации в условиях детского дома для детей с нарушениями. У большинства наших информантов их когнитивным отличиям и своеобразной социализации сопутствует в жанре рассказывания историй характерная экспрессивность речи при ее относительной бедности и в плане лексического разнообразия, и в плане способов рассказывания, основным из которых выступает анимация истории, превращающая рассказ в сценическое разыгрывание диалога персонажей. Лишь отчасти это могло бы объясняться отсутствием даже не просто образования, но навыка чтения и- по существу-начитанности.

\section{Заключение}

Собранные нами рассказы были частью неструктурированных антропологических интервью биографического характера или записаны в ходе разговоров, где исследователь был одним из участников. При всей важности характеристик собеседника как исследователя, можно предположить, что наши информанты такие же истории примерно теми же словами рассказали бы и скорее всего не раз это делали и в других ситуациях.

Уроки развития речи в школе, в которых не довелось участвовать нашим рассказчикам, целенаправленно формируют навыки развернутого монологического высказывания, ориентированного на стандарты письменной речи. Развернутость «грамотного» высказывания, письменного или устного, позволяет ему успешнее функционировать вне связи с непосредственным контекстом его порождения. Наши информанты постоянно взаимодействуют в своем кругу, куда входят другие подопечные НКО, социальные работники и педагоги, и могут лишь иногда попадать в ситуацию, когда их рассказы должны восприниматься посторонними, не входящими в близкий круг людьми. В такой ситуации рассказ, включающий биографические подробности и случаи из жизни, содержит более или менее отработанные, повторяющиеся истории, демонстрирующие самопрезентацию рассказчика.

Едва ли на основании наших материалов мы могли бы сделать далеко идущие выводы об особенностях рассказывания историй выросшими выпускниками интернатов с легкой формой задержки психического развития. Поскольку в нашем случае нет возможности сопоставить между собой рассказы из собственного жизненного опыта выпускников детских домов с достоверно диагностированной «легкой степенью умственной отсталости», с одной стороны, и без такого диагноза, с другой, у нас нет оснований связывать те характеристики рассказов, которые мы можем наблюдать, именно с особенностями этой группы информантов. Однако чем бы ни были обусловлены эти характеристики, мы могли убедиться, 
что встроенная в рассказ рефлексия, косвенная речь, подчинительные связи, не говоря уже о металингвистических высказываниях, как представляется, оказываются не актуальны для наших информантов: в них не испытывают потребности ни рассказчики, ни слушатели.

\section{Выражение признательности}

Исследование выполнено при поддержке гранта РФФИ-20-09-00063А «Инвалидность как социокультурный феномен».

Редакция благодарит программу «Университетское партнерство» за поддержку и возможность опубликовать данную статью. 
Ilya Utekhin, Anna Altukhova, Anna Klepikova

\section{INTELLECTUAL DISABILITIES AND NARRATIVES FROM PERSONAL EXPERIENCE: STORYTELLING IN ORAL DISCOURSE}

This article examines oral narratives of the personal experiences by young adults with mild intellectual disability. These narratives have been collected as semi-structured interviews and multi-party conversations. At that moment all the storytellers were involved in an assisted living project promoted by an NGO that enabled them to have left specialized institutions. Most of the informants are close to functional illiteracy due to a lack or the inadequacy of their schooling. The example analysed in the article falls into the category of life story narrative on the horrors of lived experience in a family or in an institution. The storytellers only rarely needed to represent themselves out of the circle of their own group and social workers, and the stories told appear to have circulated within this circle. We analysed the narrative discourse and arrived at the conclusion that for the storytellers under consideration, the main means to tell the story is to animate the plot, translating it into a dialog between the characters that is quoted in direct speech. We highlighted the key framing expressions and discourse markers used by the storytellers observed. Some types of framing expressions, usually reflecting the attitude of the storyteller, were absent in the stories. The narratives also demonstrate the tendency to use relations of coordination, while not using subordination to express causal meanings. However, the observations proposed in the paper cannot be interpreted as particular features of storytelling by the intellectually disabled, because no systematic comparative study has been performed involving stories by intellectually intact people with comparative experiences of socialization in specialized institutions.

Keywords: discourse, oral narrative, storytelling, intellectual disability

DOI: 10.17323/727-0634-2021-19-4-619-634

\section{References}

Angrosino M. V. (1992) Metaphors of Stigma: How Deinstitutionalized Mentally Retarded Adults See Themselves. Journal of Contemporary Ethnography, 21 (2): 171-199.

Ilya V. Utekhin- Cand. Sci. (Hist.), Associate Prof., Department of Anthropology, European University at St. Petersburg, Russian Federation.Email: ilia@eu.spb.ru, ilya.utekhin@gmail.com

Anna N. Altukhova- MA in cultural anthropology, Research Fellow, Institute for Interdisciplinary Medical Research, European University at St. Petersburg, Russian Federation. Email: aaltukhova@eu.spb.ru

Anna A. Klepikova-Cand. Sci. (Sociol.), Associate Prof., Department of Anthropology, European University at St. Petersburg, Russian Federation. Email: aklepikova@eu.spb.ru 
Angrosino M. V. (1997) The Ethnography of Mental Retardation: An Applied Perspective. Journal of Contemporary Ethnography, 26 (1): 98-109.

Eme E., Lacroix A., Almecija Y. (2010) Oral Narrative Skills in French Adults Who are Functionally Illiterate: Linguistic Features and Discourse Organization. Journal of Speech, Language, and Hearing Research, (53): 1349-1371.

Goffman E. (1974) Frame Analysis: An Essay on the Organization of Experience. New York: Harper Colophon.

Goffman E. (1981) Forms of Talk. Philadelphia: University of Pennsylvania Press.

Hunt K. (1998) Abandoned to the State: Cruelty and Neglect in Russian Orphanages. Vol. 2156. New York: Human Right Watch.

Jefferson G. (1978) Sequential Aspects of Storytelling in Conversation. In: J. Schenkein (ed.) Studies in the Organization of Conversational Interaction. New York: Academic Press: 219-248.

Labov W., Walezky J. (1967) Narrative Analysis: Oral Versions of Personal Experience. In: J. Helm (ed.) Essays on the Verbal and Visual Arts. Seattle: University of Washington Press: $12-44$.

Mandelbaum J. (2013) Storytelling in Conversation. In: J. Sidnell, T. Stivers (eds.) Handbook of Conversation Analysis. New York: Wiley Blackwell: 492-508.

Levinson S. C. (2006) On the Human 'Interaction Engine.' In: N. J. Enfield, S. C. Levinson (Cur.) (eds.) Roots of Human Sociality: Culture, Cognition and Interaction. Oxford: Berg: 39-69.

Lovell A. M. (1997) 'The City Is My Mother': Narratives of Schizophrenia and Homelessness. American Anthropologist, 99 (2): 355-368.

Ribeiro B. T. (2006) Footing, Positioning, Voice. Are We Talking about the Same Things? In: A. De Fina, D. Schiffrin,.M. Bamberg (eds.) Discourse and Identity. New York: Cambridge University Press: $48-82$.

Rockhill E. K. (2010) Lost to the State: Family Discontinuity, Social Orphanhood and Residential Care in the Russian Far East. New York, Oxford: Berghahn Books.

Sacks H. (1992) Lectures on Conversation. Vol. 2. Cambridge, MA: Blackwell.

Sacks H. (1974) An Analysis of the Course of a Joke's Telling in Conversation. In: J. Sherzer, R. Bauman (eds.) Explorations in the Ethnography of Speaking. London: Cambridge University Press: 337-353.

Schegloff E. (1997) 'Narrative Analysis' Thirty Years Later. Journal of Narrative and Life History, 7 (1-4): 97-106.

Schiffirin D. (1987) Discourse Markers. Cambridge: Cambridge University Press.

Schmidt V. (2009) Orphan Care in Russia. Social Work \& Society, 7 (1): 58-69.

Stepanova E. (2014) Understanding the Nature of Institutionalization for Children in Russia. Durham: Durham University. 